\title{
Malic Acid Attenuates Potassium Oxonate Induced Gouty Inflammation in Wistar Rat
}

\author{
Vayyattil Vijeesh ${ }^{1} \mathbb{D}$, Anandan Vysakh ${ }^{1}$, Ninan Jisha ${ }^{1}$, Mukalel Sankunni Latha ${ }^{1, *}$ iD \\ 1 School of Biosciences, Mahatma Gandhi University, Priyadarshini Hills, Kottayam, Kerala, India, \\ vijeeshvayyadan@gmail.com (V.V.), vysakh15@gmail.com (A.V.), jishaninan@gmail.com (N.J.), \\ mslathasbs@gmail.com (M.S.); \\ * Correspondence: mslathasbs@gmail.com (M.S.);
}

Scopus Author ID 55188074200

Received: 20.04.2021; Revised: 22.05.2021; Accepted: 25.05.2021; Published: 9.06.2021

\begin{abstract}
Malic acid is an organic dicarboxylic acid commonly found in vegetables and fruits. Gouty inflammation is a disease characterized by the accumulation of monosodium urate (MSU) crystals around the tissues and joints. Hence, the current study has been conducted to evaluate the antiinflammatory efficacy of the malic acid against the potassium oxonate (PO) induced animal model. The hematological, biochemical, and histopathological analyses were carried out to evaluate the efficacy of malic acid in treating gouty inflammation. The elevated levels of various biological markers such as liver injury markers (aspartate aminotransferase, alanine aminotransferase, alkaline phosphatase, bilirubin), renal function markers (urea, creatinine, uric acid), inflammatory markers (C-reactive protein and rheumatoid factors) and blood markers (hemoglobin, erythrocyte sedimentation rate) and white blood cells were observed in PO induced rats. Histological analysis also revealed inflammation in the ankle joint of PO-treated rats. The malic acid $(25,50,100 \mathrm{mg} / \mathrm{kg}$ bwt $)$ treatment made the rats regain the biological markers near to their normal values. It was revealed that the malic acid had potential antigouty inflammatory activity against PO induced rat model. Hence, malic acid can be proposed as an excellent drug molecule with detailed examinations.
\end{abstract}

Keywords: Gout; Inflammation; Potassium oxonate; Malic acid; Wistar rat.

(C) 2021 by the authors. This article is an open-access article distributed under the terms and conditions of the Creative Commons Attribution (CC BY) license (https://creativecommons.org/licenses/by/4.0/).

\section{Introduction}

Gout is an inflammatory disease which is featured by the accumulation of monosodium urate (MSU) crystals around the tissues and joints [1]. Formation of the MSU crystal is the consequence of the elevated level of uric acid in body fluid, and this clinical condition is known as hyperuricemia [2]. The MSU crystal deposition induces the inflammatory cascade and released pro-inflammatory mediators when the tissue macrophage recognizes it. These mediators activated the cytokines, followed by the release of an excess amount of neutrophil into the synovium and affected tissues, thereby inducing inflammation-mediated clinical complications such as joints destruction, tissue damage, etc. [3,4]. Gout is associated with many risk factors, including kidney dysfunction, cardiovascular dysfunction, diabetes, hypertension, and other comorbid conditions [5-7]. A combined treatment strategy (blood urate-lowering treatment and the use of anti-inflammatory drugs) is currently effective against gouty inflammation and its associated diseases [8]. Various anti-inflammatory drugs (colchicine, nonsteroidal anti-inflammatory drugs, and glucocorticoids ) used to treat gouty inflammation exerts severe side effects such as renal toxicity or gastrointestinal bleeding, etc. 
[9-11]. Hence, a better drug alternative with good efficacy and fewer side effects is a better choice for the treatment.

Natural biomolecules have boundless unexplored biological activities, and many are currently considered as lead drug molecules [12]. Malic acid is an organic dicarboxylic acid commonly found in vegetables and fruits. It is an inevitable component in the food, beverage, cosmetics industry and is used as a taste enhancer, food acidulant, and food preservative $[13,14]$. The malic acid, its combined form with citric acid and succinic acid, exhibited antithrombotic, antiplatelet, antiproliferative, antixerostomia activities, and protective effect on myocardial ischemia/reperfusion injury [15-18]. The anti-inflammatory effect of malic acid in association with gout is not well studied yet. The present work focused on examining the antigouty inflammatory activity of malic acid in a potassium oxonate-induced animal model.

\section{Materials and Methods}

\subsection{Chemicals.}

Malic acid was purchased from Sigma-Aldrich (Spruce Street, St. Louis, MO, USA). The potassium oxonate was procured from Sigma-Aldrich (Spruce Street, St. Louis, MO, USA). All other chemicals used were of analytical grade, and ultrapure water was used for the study.

\subsection{Experimental animals.}

Male Wistar rats were procured from the small animal breeding station (SABS), Kerala Veterinary and Animal Sciences University, Mannuthy, Thrissur, Kerala. The animals were maintained in polypropylene cages under controlled room temperature $\left(22 \pm 2^{\circ} \mathrm{C}\right)$ and humidity $(55 \pm 5 \%)$ with a $12 \mathrm{~h}$ light and $12 \mathrm{~h}$ dark cycle. All the rats were fed with normal rat pellet obtained from VRK's Scientists' choice laboratory animals feed- VRK Nutritional solutions, Maharashtra, India. The water was provided ad-libitum throughout the experimental period. The study protocol was approved by the Institutional Animal Ethical Committee, School of Biosciences, Mahatma Gandhi University (Reg. No. IAEC No: 23092019-2) according to the Government of India accepted principles for laboratory animals' use and care.

\subsection{Experimental design.}

Wistar rats (130-150 g) were randomly divided into six groups, and each group contained six rats.

Group I: Normal control (NC)

Group II: Potassium oxonate (PO) treated disease control ( $250 \mathrm{mg} / \mathrm{kg}$ bwt intraperitoneally)

Group III: PO+Indomethacin (3mg/kg bwt orally)

Group IV: PO+ malic acid (25mg/kg bwt orally)

Group V: PO+ malic acid (50mg/kg bwt orally)

Group VI: PO+ malic acid (100mg/kg bwt orally)

The PO, indomethacin, and malic acid were administrated once a day for the 28 days of the experimental period. 


\subsection{Experimental parameters.}

The blood (white blood cell count (WBC), hemoglobin content $(\mathrm{Hb})$, erythrocyte sedimentation rate (ESR)), renal (creatinine, blood urea nitrogen (BUN), blood urea, uric acid, etc.) and liver functional (aspartate transaminase (AST), alanine transaminase (ALT), alkaline phosphatase (ALP), total bilirubin) markers were analyzed using standard diagnostic kits procured from Span Diagnostics Limited, Surat, India. The inflammatory markers such as Creactive protein(CRP) and Rheumatoid factor (RF) were measured by using DiaSys Diagnostic kit (Germany). UV-Vis spectrophotometer (U-5100, Hitachi High Technologies, America, Inc.) was used for the absorbance measurement. The histopathological changes associated with gouty inflammation in the ankle joints were examined using the hematoxylin and eosin (H\&E) staining.

\subsection{Statistical analysis.}

The statistical analysis was made using the GraphPad Prism(C) version 5.03 for Windows (GraphPad Software, San Diego, CA, USA). All the data have been expressed as mean \pm standard deviation. The statistical significance between the groups was analyzed by One way- ANOVA. The P-value less than $0.05(\mathrm{P}<0.05)$ was considered significant.

\section{Results and Discussion}

Gout is a systemic inflammatory disease caused by the deposition of monosodium urate crystals in the joints [19]. The socio-economic burden of gout and related diseases is gradually increasing, with an estimated global prevalence rate of $1 \%$ to $6.8 \%$ [20]. The elevated level of uric acid in the body fluid initiates the MSU crystal formation [21]. When the macrophage recognizes the MSU crystals, it activates the NLRP3 inflammasomes and pro-inflammatory cytokines [22]. The matured pro-inflammatory mediator (IL-1 $\beta$ ) induces the influx of neutrophils infiltration into the inflamed site [23]. This inflammatory cascade led to clinical complications such as pain, swelling, tissue damage, and joint distortion [24,25]. Lowering urate levels and using anti-inflammatory drugs combined is the effective treatment strategy adopted nowadays to manage gouty inflammation. Using drugs such as allopurinol, corticosteroid, and nonsteroidal anti-inflammatory drugs to treat gout has some adverse side effects [26]. Hence, the current study examines the anti-gout activity of malic acid against the potassium oxonate-induced gouty inflammation in the animal model. The results obtained from the current study revealed that the malic acid exerts potential anti-gouty inflammation activity.

Abnormal levels of creatinine, BUN, blood urea and uric acid were found in body fluids when the kidneys are not functioning properly or if there is any damage to the kidneys [27]. Such conditions are a cautionary sign of many diseases, the most important of which is inflammation. The elevated uric acid levels can cause hyperuricemia, a metabolic disorder that can lead to other related diseases like gouty arthritis etc. [28]. Experimental rats were found to have elevated creatinine levels, BUN, blood urea, and uric acid due to PO treatment. In the present study, we found that renal function markers elevated in the disease were retained near to its normal levels upon treatment with malic acid $(25,50,100 \mathrm{mg} / \mathrm{kg}$ bwt concentrations) (Figure 1,2). Based on these results, it can be said that malic acid has the ability to restore the normal functioning of the kidneys.

Group II showed significantly $(\mathrm{P}<0.05)$ higher levels of liver function markers (AST, ALT, ALP, and Bilirubin) of liver functions compared to the normal group. With the treatment 
of standard drug and malic acid, the level of liver function markers decreased and came close to the normal level (Group III to Group VI) (Figure 2,3). The liver plays a significant role in the metabolic process. It is adequate to check the level of the liver function markers in serum to evaluate the functional aspect of the liver. The elevated liver function markers such as AST, ALT, ALP, and total bilirubin in serum were considered as an indication of abnormal liver functioning or liver injury [29]. The abnormal levels of liver function markers were found in rats treated with PO. In addition, it reduced near the normal range in rats treated with malic acid.

Hematological parameters such as ESR, $\mathrm{Hb}$, and WBC count were found to be elevated in rats induced with potassium oxonate. After treatment with malic acid, the concentration of hematological parameters was found to be near to its normal level. (Table 1). The ESR, Hb level and WBC count are the important hematological parameters associated with inflammation. Hematological markers are found in higher levels in body fluids when there is any tissue injury or inflammation[27]. In the present study, rats treated with PO increased their ESR, Hb, and WBC levels. However, in PO-induced rats treated with malic acid, the level of hematological markers was found to be lower and closer to the normal range. These findings strengthen the anti-inflammatory properties of malic acid.

Increased levels of inflammatory markers such as CRP and RF were observed in the potassium oxonate treated groups. Treatment with malic acid found that the level of inflammatory markers decreased close to its normal (Figure 4, 5). The CRP and RF are considered to be an important biomarkers of inflammatory diseases[30]. In this clinical condition, pro-inflammatory cytokines (IL-6) cause high levels of CRP and RF in the blood. Higher levels of RF and CRP in PO-induced rats were observed in the present study. These elevated levels of RF and CRP got back near to its normal value after the treatment with malic acid.

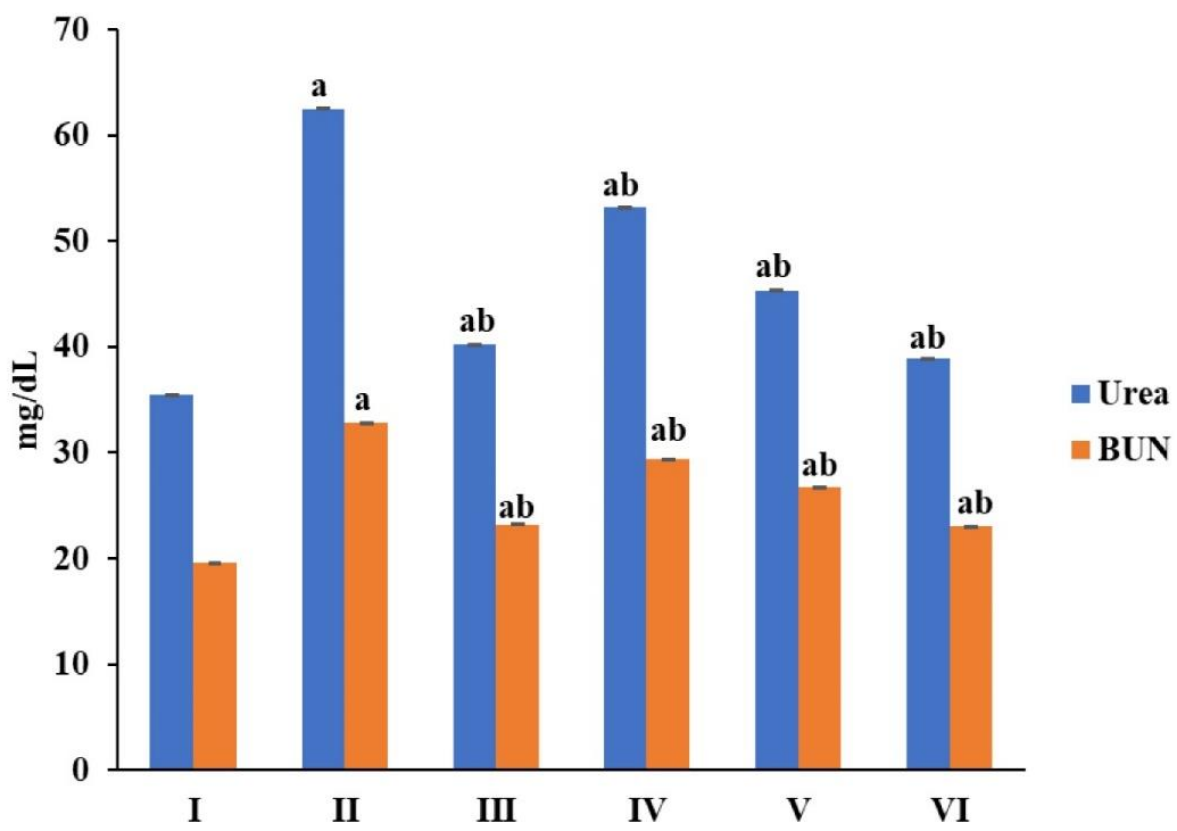

Figure 1. Effect of malic acid on urea and BUN in different experimental groups. Values are expressed Mean \pm $\mathrm{SD}$ value, $\mathrm{n}=6$ in each group. ${ }^{\mathrm{a}}$ and ${ }^{\mathrm{b}}$ represent the statistical difference with a normal group and statistical difference with disease group, respectively $(\mathrm{P}<0.05)$.

The outer dense connective tissue and the inner layer of the synovial membrane (SM) in the joint capsule are usually found in the ankle joint of the normal experimental rat. A thin layer of synovial epithelium that overlying the connective tissue (CT) was observed in the 
normal rats. In the event of an injury or other inflammation in the ankle, it affects the normal function and structure [31]. The important characteristic feature of gouty inflammation is the hyperplastic synovial membrane and the inflammatory cell infiltration. Potassium oxonateinduced rats were found to have a thicker synovial membrane (synovial hyperplasia (SH)) and moderate inflammatory cell infiltration in the ankle. The treatment with malic acid retained the normal structure of tissues compared with the histological changes in the PO-induced group. The malic acid-treated group exhibited a normal structure of the synovial membrane, joint cavity, chondrocytes, trabecula, and connective tissue (Figure 6). These results revealed the anti-gouty inflammatory activity of malic acid.

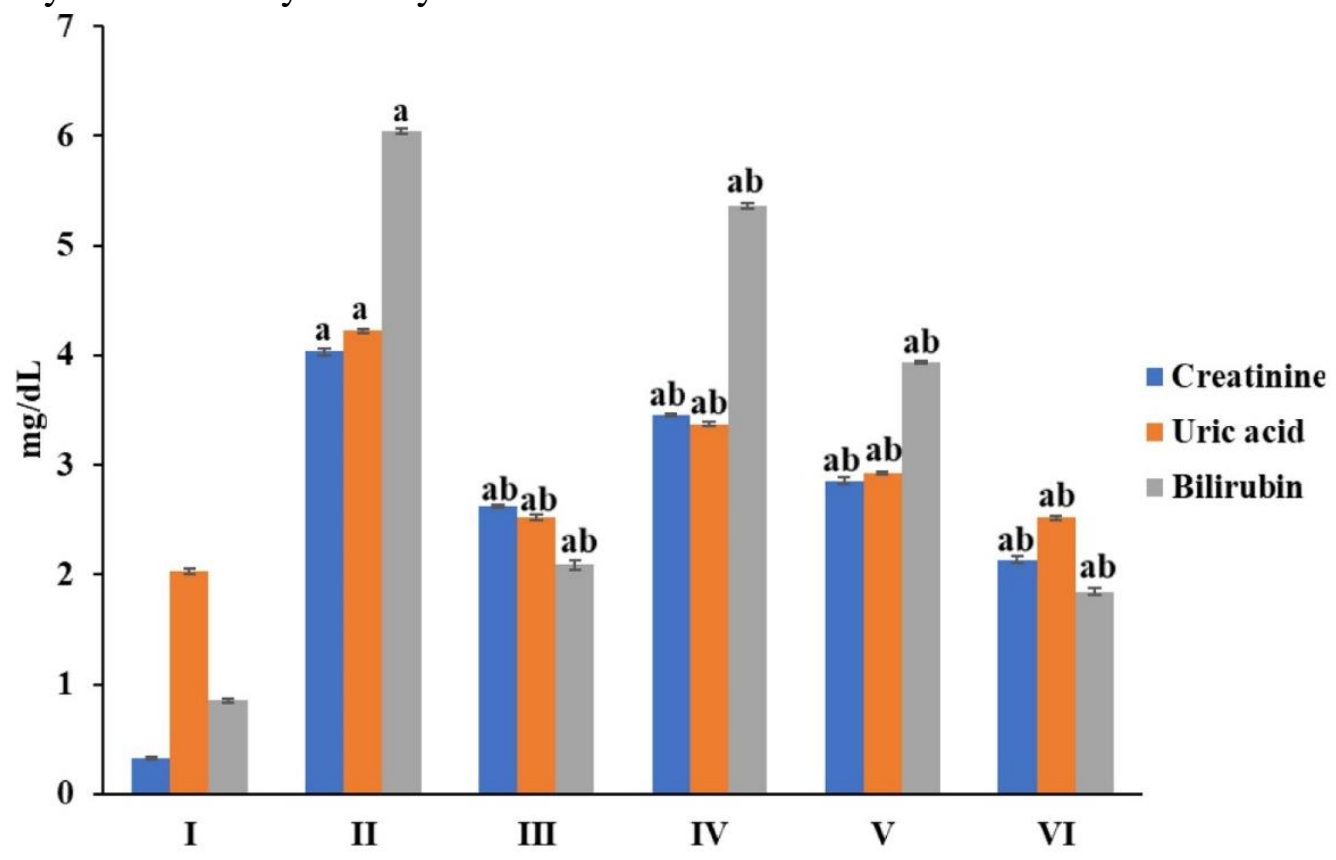

Figure 2. Effect of malic acid on creatinine, uric acid and bilirubin in different experimental groups. Values are expressed Mean \pm SD value, $n=6$ in each group. ${ }^{\mathrm{a}}$ and ${ }^{\mathrm{b}}$ represent the statistical difference with a normal group and statistical difference with disease group, respectively $(\mathrm{P}<0.05)$.

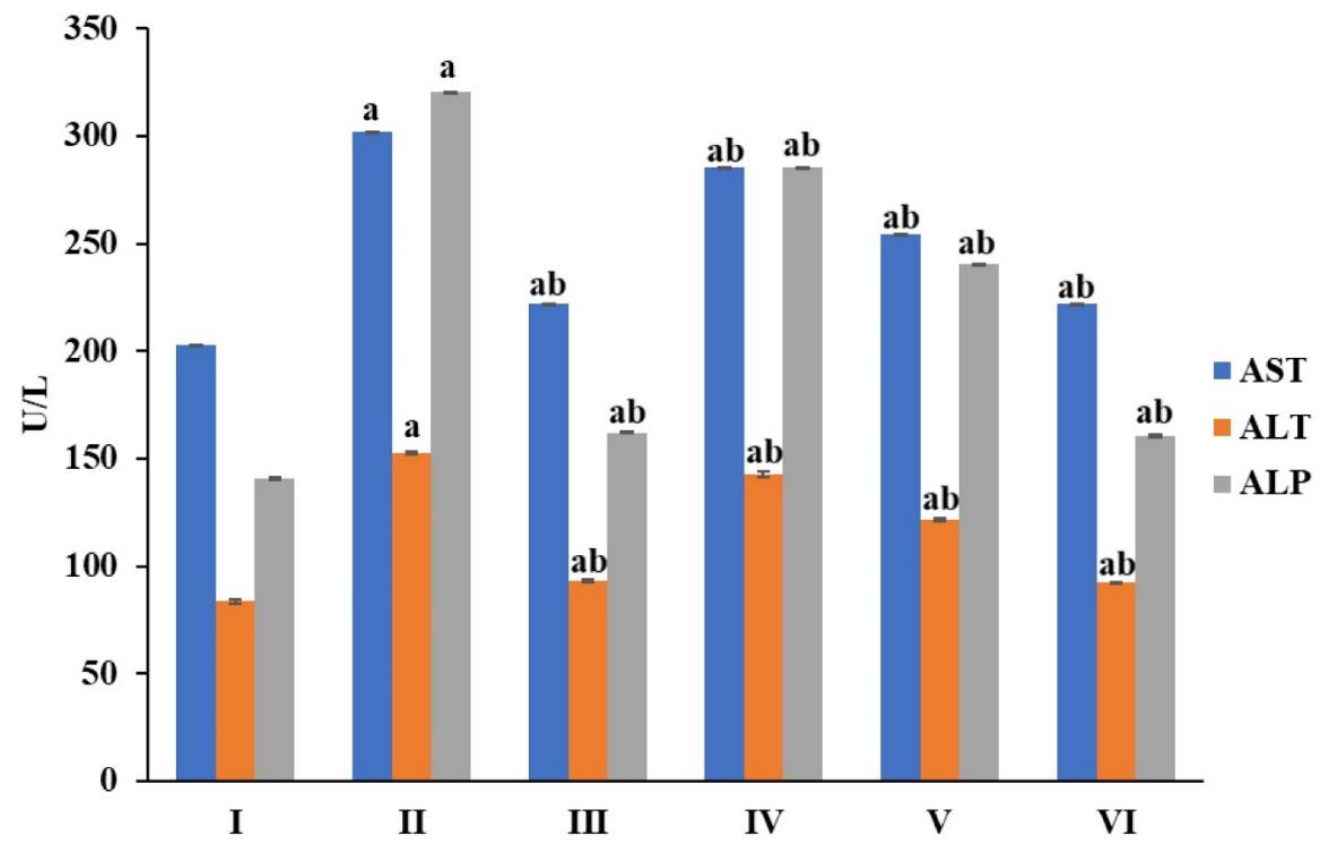

Figure 3. Effect of malic acid on liver function markers in different experimental groups. Values are expressed Mean \pm SD value, $n=6$ in each group. ${ }^{\mathrm{a}}$ and ${ }^{\mathrm{b}}$ represent the statistical difference with a normal group and statistical difference with disease group, respectively $(\mathrm{P}<0.05)$. 


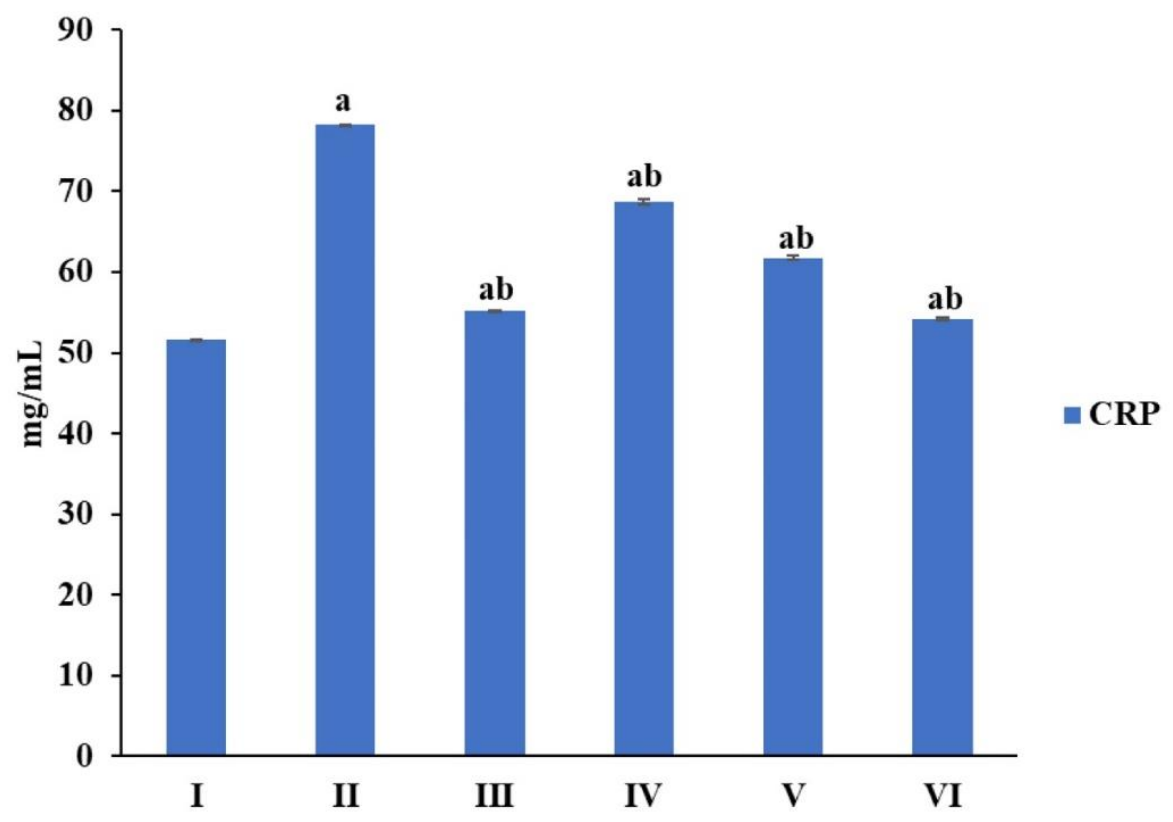

Figure 4. Effect of malic acid on CRP in different experimental groups. Values are expressed mean \pm SD value, $\mathrm{n}=6$ in each group. ${ }^{\mathrm{a}}$ and ${ }^{\mathrm{b}}$ represent the statistical difference with a normal group and statistical difference with disease group respectively $(\mathrm{P}<0.05)$.

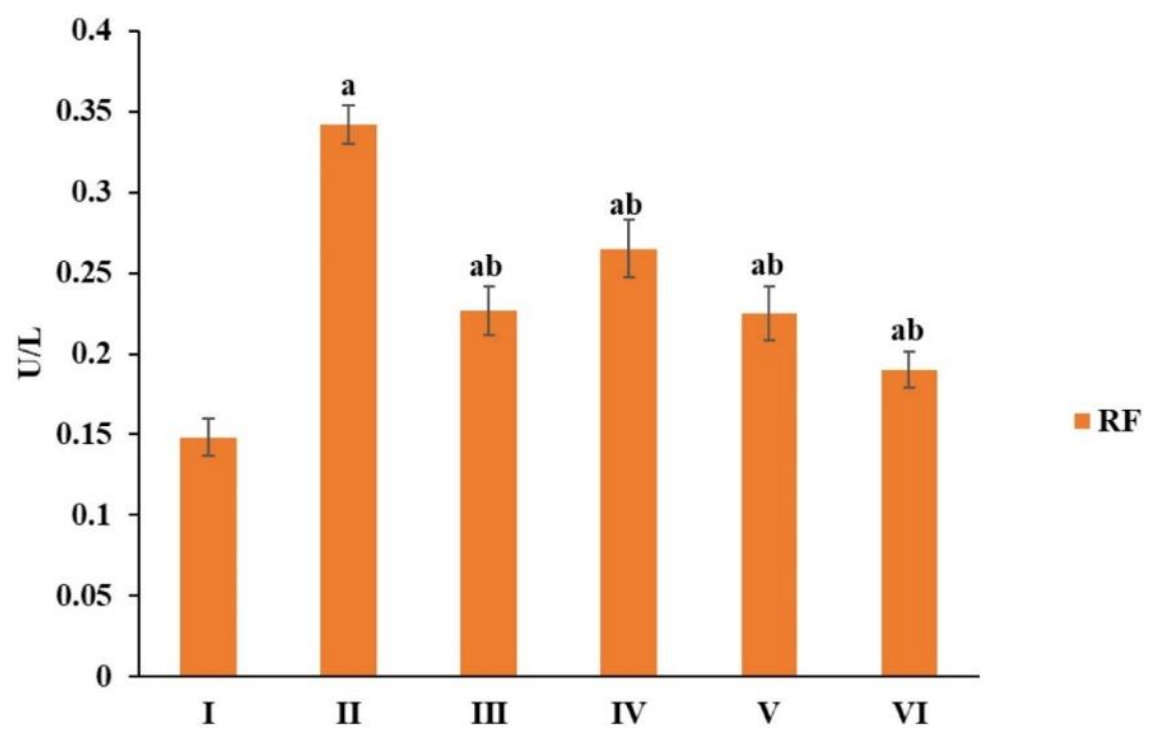

Figure 5. Effect of malic acid on RF in different experimental groups. Values are expressed mean \pm SD value, $n$ $=6$ in each group. ${ }^{\mathrm{a}}$ and ${ }^{\mathrm{b}}$ represent the statistical difference with a normal group and statistical difference with disease group, respectively $(\mathrm{P}<0.05)$.

Table 1. Hematological parameters evaluation in different experimental groups.

\begin{tabular}{l|l|l|l} 
Experimental groups & $\begin{array}{l}\text { ESR } \\
(\mathbf{m m} / \mathbf{h r})\end{array}$ & $\begin{array}{l}\text { Hb } \\
(\mathbf{g} / \mathbf{d L})\end{array}$ & $\begin{array}{l}\text { Leukocytes } \\
(\mathbf{x 1 0} / \boldsymbol{\mu} \mathbf{L})\end{array}$ \\
\hline Group-I & $1.18 \pm 0.01$ & $17.32 \pm 0.01$ & $5.65 \pm 0.03$ \\
\hline Group-II & $5.34 \pm 0.01^{\mathrm{a}}$ & $15.24 \pm 0.02^{\mathrm{a}}$ & $17.34 \pm 0.03^{\mathrm{a}}$ \\
\hline Group-III & $2.36 \pm 0.01^{\mathrm{ab}}$ & $16.94 \pm 0.01^{\mathrm{ab}}$ & $8.24 \pm 0.02^{\mathrm{ab}}$ \\
\hline Group-IV & $4.83 \pm 0.02^{\mathrm{ab}}$ & $15.70 \pm 0.07^{\mathrm{ab}}$ & $13.29 \pm 0.04^{\mathrm{ab}}$ \\
\hline Group-V & $3.43 \pm 0.02^{\mathrm{ab}}$ & $16.46 \pm 0.02^{\mathrm{ab}}$ & $11.21 \pm 0.06^{\mathrm{ab}}$ \\
\hline Group-VI & $2.25 \pm 0.03^{\mathrm{ab}}$ & $16.91 \pm 0.01^{\mathrm{ab}}$ & $8.08 \pm 0.05^{\mathrm{ab}}$
\end{tabular}

Values are expressed mean $\pm \mathrm{SD}$ value, $\mathrm{n}=6$ in each group. ${ }^{\mathrm{a}}$ and ${ }^{\mathrm{b}}$ represent the statistical difference with a normal group and statistical difference with disease group, respectively $(\mathrm{P}<0.05)$. 

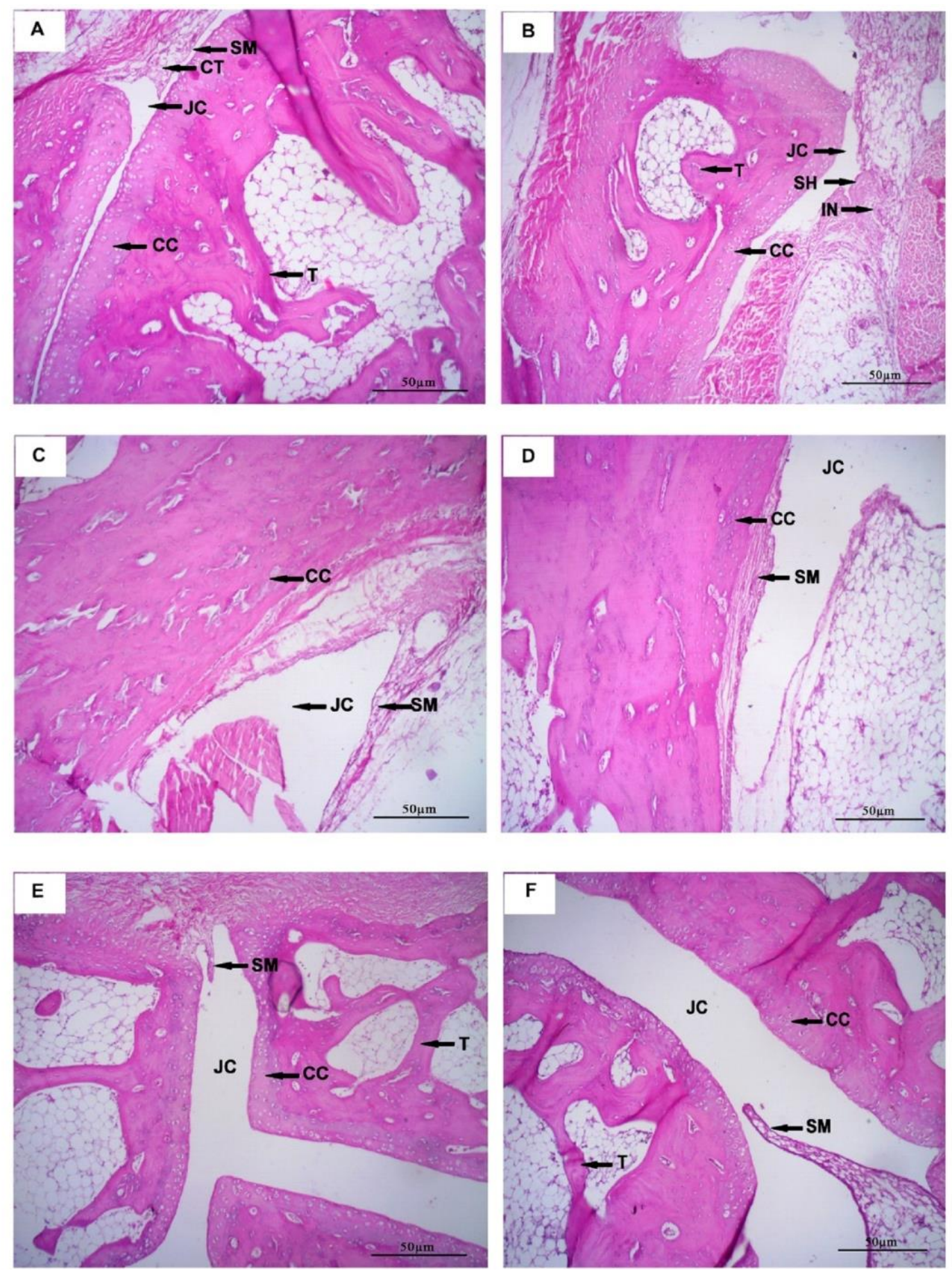

Figure 6. Histological evaluation of synovium in different experimental groups. SM: Synovial Membrane, JC: Joint Cavity, CC: Chondrocytes, T: Trabecula, SH:Synovial Hyperplasia, IN: Inflammation, CT: Connective Tissue. . A: Group I; B: Group II; C: Group III; D: Group IV; E: Group V; F: Group VI.

\section{Conclusions}

Based on the current findings, it can be concluded that malic acid can normalize the ill effects associated with gouty inflammation to an extent. The properties exhibited by malic acid made it be used as an enviable component in our daily diet. Suppose the detailed studies (the molecular level mechanism and other pharmacological evaluation) are successful. In that case, the malic acid will prove its efficacy to act as a promising therapeutic agent for gout and its associated diseases. Hence these studies could be a great relief for those who are the victim of such diseases. 


\section{Funding}

This research received no specific grant from any funding agency.

\section{Acknowledgments}

The authors are thankful to the School of Biosciences, Mahatma Gandhi University, India, for providing excellent research support.

\section{Conflicts of Interest}

The authors declare that they have no conflict of interest.

\section{Ethics declarations}

Animal ethical: The study protocol was approved by the Institutional Animal Ethical Committee, School of Biosciences, Mahatma Gandhi University (Reg. No. IAEC No: 23092019-2) according to the Government of India accepted principles for laboratory animals' use and care.

\section{References}

1. Ayoub, S.; Rajamohan, A.G.; Acharya, J.; Gross, J.; Patel, V. Chronic tophaceous gout causing lumbar spinal stenosis. Radiology Case Reports 2021, 16, 237-240, https://doi.org/10.1016/j.radcr.2020.11.017.

2. Martins de Sá Müller, C.; Coelho, G.B.; Carolina de Paula Michel Araújo, M.; Saúde-Guimarães, D.A. Lychnophora pinaster ethanolic extract and its chemical constituents ameliorate hyperuricemia and related inflammation. J. Ethnopharmacol. 2019, 242, 112040, https://doi.org/10.1016/j.jep.2019.112040.

3. Fernandes, M.J.; Naccache, P.H. The Role of Inhibitory Receptors in Monosodium Urate Crystal-Induced Inflammation. Front. Immunol. 2018, 9, 1883, https://doi.org/10.3389/fimmu.2018.01883.

4. Paul, S.; Kulal, R.; Nath, R. Comparative evaluation of expression of VEGF (vascular endothelial growth factors) in periodontal tissues of healthy, chronic and aggressive periodontitis patients: an immunohistochemical study. Letters in Applied NanoBioScience 2020, 9, 784-788, https://doi.org/10.33263/lianbs91.784788.

5. Wu, M.; Tian, Y.; Wang, Q.; Guo, C. Gout: a disease involved with complicated immunoinflammatory responses: a narrative review. Clin. Rheumatol. 2020, 39, 2849-2859, https://doi.org/10.1007/s10067-02005090-8.

6. Kaul, S.; Gupta, M.; Bandyopadhyay, D.; Hajra, A.; Deedwania, P.; Roddy, E.; Mamas, M.; Klein, A.; Lavie, C.J.; Fonarow, G.C.; Ghosh, R.K. Gout Pharmacotherapy in Cardiovascular Diseases: A Review of Utility and Outcomes. Am. J. Cardiovasc. Drugs 2020, https://doi.org/10.1007/s40256-020-00459-1.

7. Borghi, C.; Agabiti-Rosei, E.; Johnson, R.J.; Kielstein, J.T.; Lurbe, E.; Mancia, G.; Redon, J.; Stack, A.G.; Tsioufis, K.P. Hyperuricaemia and gout in cardiovascular, metabolic and kidney disease. Eur. J. Intern. Med. 2020, https://doi.org/10.1016/j.ejim.2020.07.006.

8. Latourte, A.; Bardin, T.; Richette, P. Prophylaxis for acute gout flares after initiation of urate-lowering therapy. Rheumatology 2014, 53, 1920-1926, https://doi.org/10.1093/rheumatology/keu157.

9. Joshi, T.; Sharma, P.; Joshi, T.; Chandra, S. In silico screening of anti-inflammatory compounds from Lichen by targeting cyclooxygenase-2. J. Biomol. Struct. Dyn. 2020, 38, 3544-3562, https://doi.org/10.1080/07391102.2019.1664328.

10. Lelièvre, B.; Drouillard, I.; Thill, C.; Le Roux, G.; Bruneau, C.; Mahé, J.; Deguigne, M.; Boels, D. Severe poisoning with naproxen causing coagulopathy. Basic Clin. Pharmacol. Toxicol. 2020, 126, 458-463, https://doi.org/10.1111/bcpt.13365.

11. Yao, R.; Geng, Z.; Mao, X.; Bao, Y.; Guo, S.; Bao, L.; Sun, J.; Gao, Y.; Xu, Y.; Guo, B.; Meng, F.; Cui, X. Tu-Teng-Cao Extract Alleviates Monosodium Urate-Induced Acute Gouty Arthritis in Rats by Inhibiting Uric Acid and Inflammation. Evid. Based Complement. Alternat. Med. 2020, 2020, 3095624, https://doi.org/10.1155/2020/3095624. 
12. Tang, H.; Zhao, D. Investigation of the interaction between salvianolic acid C and xanthine oxidase: Insights from experimental studies merging with molecular docking methods. Bioorg. Chem. 2019, 88, 102981, https://doi.org/10.1016/j.bioorg.2019.102981.

13. Iyyappan, J.; Baskar, G.; Gnansounou, E.; Pandey, A.; Raaman, J.K.; Bharathiraja, B.; Praveenkumar, R. Recent advances in microbial production of malic acid from renewable byproducts. Reviews in Environmental Science and Bio/Technology 2019, 18, 579-595, https://doi.org/10.1007/s11157-019-09503-2.

14. Lee, B.; Heo, J.; Hong, S.; Kim, E.-Y.; Sohn, Y.J.; Jung, H.-S. dl-Malic acid as a component of $\alpha$-hydroxy acids: effect on 2,4-dinitrochlorobenzene-induced inflammation in atopic dermatitis-like skin lesions in vitro and in vivo. Immunopharmacol. Immunotoxicol. 2019, 41, 614-621, https://doi.org/10.1080/08923973.2019.1680688.

15. Tiptiri-Kourpeti, A.; Fitsiou, E.; Spyridopoulou, K.; Vasileiadis, S.; Iliopoulos, C.; Galanis, A.; Vekiari, S.; Pappa, A.; Chlichlia, K. Evaluation of Antioxidant and Antiproliferative Properties of Cornus mas L. Fruit Juice. Antioxidants 2019, 8, https://doi.org/10.3390/antiox8090377.

16. Tang, X.; Liu, J.; Dong, W.; Li, P.; Li, L.; Lin, C.; Zheng, Y.; Hou, J.; Li, D. The Cardioprotective Effects of Citric Acid and L-Malic Acid on Myocardial Ischemia/Reperfusion Injury. Evid. Based Complement. Alternat. Med. 2013, 2013, 820695, https://doi.org/10.1155/2013/820695.

17. Zhang, Q.-C.; Zhao, Y.; Bian, H.-M. Antiplatelet Activity of a Novel Formula Composed of Malic Acid, Succinic Acid and Citric Acid from Cornus officinalis Fruit. Phytother. Res. 2013, 27, 1894-1896, https://doi.org/10.1002/ptr.4934.

18. Izquierdo-Vega, J.A.; Arteaga-Badillo, D.A.; Sánchez-Gutiérrez, M.; Morales-González, J.A.; VargasMendoza, N.; Gómez-Aldapa, C.A.; Castro-Rosas, J.; Delgado-Olivares, L.; Madrigal-Bujaidar, E.; Madrigal-Santillán, E. Organic Acids from Roselle (Hibiscus sabdariffa L.) —A Brief Review of Its Pharmacological Effects. Biomedicines 2020, 8, https://doi.org/10.3390/BIOMEDICINES8050100.

19. Hidayat, R.; Reagan, M.; Hayati, L. Tempuyung Leaves (Sonchus arvensis) Ameliorates Monosodium Urate Crystal-Induced Gouty Arthritis in Rats through Anti-Inflammatory Effects. Open Access Macedonian Journal of Medical Sciences 2020, 8, 220-224, https://doi.org/10.3889/oamjms.2020.3801.

20. Dehlin, M.; Jacobsson, L.; Roddy, E. Global epidemiology of gout: prevalence, incidence, treatment patterns and risk factors. Nature Reviews Rheumatology 2020, 16, 380-390, https://doi.org/10.1038/s41584-0200441-1.

21. Pillinger, M.H.; Mandell, B.F. Therapeutic approaches in the treatment of gout. Semin. Arthritis Rheum. 2020, 50, S24-S30, https://doi.org/10.1016/j.semarthrit.2020.04.010.

22. Chuang, J.-P.; Kao, C.-Y.; Lee, J.-C.; Ling, P.; Maa, M.-C.; Leu, T.-H. EPS8 regulates an NLRP3 inflammasome-independent caspase-1 activation pathway in monosodium urate crystal-treated RAW264.7 macrophages. BBRC 2020, 530, 487-493, https://doi.org/10.1016/j.bbrc.2020.05.084.

23. So, A.K.; Martinon, F. Inflammation in gout: mechanisms and therapeutic targets. Nature Reviews Rheumatology 2017, 13, 639-647, https://doi.org/10.1038/nrrheum.2017.155.

24. He, L.; Fan, D.; Liang, W.; Wang, Q.; Fang, J. Matrix Metalloproteinase-Responsive PEGylated Lipid Nanoparticles for Controlled Drug Delivery in the Treatment of Rheumatoid Arthritis. ACS Applied Bio Materials 2020, 3, 3276-3284, https://doi.org/10.1021/acsabm.0c00242.

25. Hemalatha, S.; Shaheedha, S.M. Comparative anti-inflammatory evaluation of five plants of Solanaceae members. International Journal of Pharmacometrics and Integrated Biosciences 2020, 5, 12-15, https://doi.org/10.26452/ijpib.v5i1.1209.

26. Palani, T.; Shobha, K.; Thirunavukkarasu, P.; Hari, R. In vitro and In silico Antigout arthritic activities of Ethanolic and Aqueous stem extracts of Cissus quadrangularis-A TLR2 and TLR4 Receptor approach. Journal of Applied Pharmaceutical Science 2018, 8, 015-022, https://doi.org/10.7324/JAPS.2018.8904.

27. Sarvaiya, V.N.; Sadariya, K.A.; Pancha, P.G.; Thaker, A.M.; Patel, A.C.; Prajapati, A.S. Evaluation of antigout activity of Phyllanthus emblica fruit extracts on potassium oxonate-induced gout rat model. Veterinary world 2015, 8, 1230, https://doi.org/10.14202/vetworld.2015.1230-1236.

28. Liu, N.; Meng, B.; Zeng, L.; Yin, S.; Hu, Y.; Li, S.; Fu, Y.; Zhang, X.; Xie, C.; Shu, L.; Yang, M.; Wang, Y.; Yang, X. Discovery of a novel rice-derived peptide with significant anti-gout potency. Food Funct. 2020, 11, 10542-10553, https://doi.org/10.1039/d0fo01774d.

29. Mustafa Kiyani, M.; Sohail, M.F.; Shahnaz, G.; Rehman, H.; Akhtar, M.F.; Nawaz, I.; Mahmood, T.; Manzoor, M.; Imran Bokhari, S.A. Evaluation of Turmeric Nanoparticles as Anti-Gout Agent: Modernization of a Traditional Drug. Medicina 2019, 55, https://doi.org/10.3390/medicina55010010. 
30. Kalsait, R.P.; Khedekar, P.B.; Saoji, A.N.; Bhusari, K.P. Role of C-reactive protein in the development of atherosclerosis in diet-induced lipidemia in albino rats. Tropical Journal of Pharmaceutical Research 2011, 10, 41-45. https://doi.org/10.4314/tjpr.v10i1.7.

31. Patel, S.S.; Shah, P.V. Evaluation of anti-inflammatory potential of the multidrug herbomineral formulation in male Wistar rats against rheumatoid arthritis. J. Ayurveda Integr. Med. 2013, 4, 86-93, https://doi.org/10.4103/0975-9476.113869. 